Szczepan W. Ślaga

\title{
SYSTEM APPROACH TO TELEONOMY OF BIOLOGICAL ORGANIZATION
}

Summary. The paper deals with natural immanent teleology of biosystems. With respect to M. Bunge's view of theoretical constructs the author takes a systeminformational theory of bioorganization and search the factual references in the form of real objects and processes exhibiting the features of goal-directed activities.

Equifinality as a main feature of open and dynamic systems is proposed to be related to the idea of a program bearing information. An internal dynamics and the coordination of different processes in biosystems takes place under the influence of diverse regulations and control mechanisms with the latter acting as a result of adequate internal or external information. We therefore may say that processes in biosystems are accomplishing in accordance with that program and are directed to the goal inducated by information encoded in this program.

The specific organization of biosystems and biological processes seems to be the foundation of teleology in biology. This organization is the empirical basis and the factual reference of teleological statements and a starting-point for formulation of criteria of an approval of these systems as teleonomic and processes as goal-directed ones. The problem of teleological explanation is not analysed here.

\section{PRELIMINARY DEFINITONS AND DEMARCATION}

On purposefulness one has written so much that we could fill with the books and papers quite a big library. Yet the problem of purposefulness of nature is still as much puzzling and intriguing as it was at Aristotle's times. It look as if

68 -paraphrasing the words of Teilhard de Chardin-after getting to a certain point in explanation of the problem we do not more any step further, but continue to shift around some inexplicable mistery inherited after ages of discussions and disputes. It may be so, because the methods of the natural research and the philosophical analysies have given us all we could expect and the further progress is possible on the condition that we employ a new approach to this problem.

When we say about teleology (finalism) we usually mean a point of view according to witch purposefulness explains the essence and course of phenomena and processes in nature. Purposefulness we generally understand as a fact of aiming at a goal, property of something that aims at some goal, adaptation (conformity and efficiency) of the ways of reaching an aim (Lalande 1962:355). It is also understand as an adaptation of parts to a whole or the parts to one another or as an adaptation of certain structures and functions to the future conditions which are not the causes of this adaptation (Lalande 1962: 356). 
But the aim itself we treat as a point (state) of destination to which an object or a process makes its way or as the end, the effect of intentional or directed activity, presumed result of the aiming. Sometimes the concepts of purpose and purposefulness are used interchangeably and even they identify with each other, especially when with the concept of purpose we define the structure of activity.

Presented here and similar definitions of purpose and purposefulness generate a whole set of questions corresponding to the concepts of plan, order, adaptation, purposely directed activity, functions etc. and concerning both the way and the range of their employment in many different domains - objects, structures, reactions, activities, behaviours - and various interpretations and ways of explanations.

In this connection in many general definitions we have metaphysical, cosmological, transcendental, immanent, inner and outer, vitalistic and psycho- vitalistic teleologies and their particular types or kinds concerning both the whole cosmos, the material world as a whole and the only living world or at last we limit them to man itself and his rational and free activities as the only purposeful. When we say about these differentiations and factual references we should include the fact that purposefulness is treated by some to be subjective or objective and by some as an existence or non-existence of so-called purposive facts as a definite type of theoretical or ontological interpretations or at last as a method of final description or teleological explanation. These latter ones are treated or as an autonomic non-reductive in relation to the causal explanations or complementary to them.

As we can notice the whole set of questions about purposefulness and consequently the attempts to answer them in different works are or obiective, empirical or methodological and epistemological or at last philosophical and even ideological one. This all shows that - as Wuketits pointed out (1980: 278) - teleology has become a pretty troublesome problem generating the controversies with an emotional tinge and for some it is directly a symbol of musty way of thinking.

Even if we omit the attitudes totally negating the fact of the teleology of nature and the extremely onesided interpretations we still have different points of view in the vital matters concerning the essence of purposefulness. They come from the complexity of the problem, the serious terminological divergences and the acceptation of various often opposing initial assumptions both epistemological and ontological.

\section{PROBLEM OF FACTUAL TELEOLOGICAL REFERENCES}

In order avoid frequent misunderstanding and for the proper setting of our further analysies we limit ourselves to the teleology concerning the living nature. But even this limitation to the biological purposefulness will not be sufficient to the univocal outline of the subject of our research. We all know very well that a biologist has to do with a great number and differences of both phenomena, processes, activities, reactions, functions and objects structures, parts etc., and not to all and to the same degree we can attribute a purposive property. But when the given class of objects or events show in fact the 
purposive character then we have the problem of their description and explanation. So we have to do on one hand with the purposive facts and on the other hand with the theories explaining or interpreting these facts with the concept of purposefulness. These theories differ from one another because they come from the various types of methodologicalepistemological or ontological assumptions. Although with the theories of natural sciences those assumptions are as a rule unverifiable they do not discredit their scientific character (Ślaga 1989: 170), but only add an unque tinge to them.

Presented interpretation is a characteristic theoretical attitude to the purposive facts, excluding both pure subjective, creationistic, vitalistic etc. approaches. Instead of employing a concept of the immanent teleology which makes us think of both the philosophical and ideological interpretations and analogy with the intentional process of purposive human activity, it would be better to name it after Woodger (1967: 436) and Ayala (1974: 12) the inner teleology. According to the opinions of many biologists biological structures and processes characteristic of some organisms show inner teleology, which does not concern any conscious intentions or intentional anticipations of a purpose and which is often defined as "purposive activity" (W.E. Agar 1943, E. S. Russel 1945), specific for the world of living beings (Goudge 1967: 193-194). The inner teleology is called by Ayala natural in opposition to the outer one, artificial, characteristic of some systems being the effect of the conscious human activity and realizing the goals imposed on them (Ayala 1974: 12; 1989: 190). It seems 
that the given definitions, though they needs further specyfying they show well the character of organisms and their parts as the only natural systems revealling goaldirectedness and the natural inner teleology.

When we carry on with indicated delineation we should yet concentrate on the fact that as a rule methodologists and philosophers (J.V. Canfield, M. Beckner, E. Nagel, M. Grene, W. C. Wimsatt, R. B. Braitwaite) make analysies of logical structure of the teleological explanation relaying to biologists (Th. Dobzhansky, F. J. Ayala, E. Mayr) the matter of empirical basis of this explanation. But biologists in they professional interests are concentrated mainly on evolution and the possibility of teleological explanation of the action of natural selection.

Many biologists seem to accept the purposive activity of biosystems and they try to explain that fact historically by showing the influence of natural selection as the basic cause of its appearence. The classical example of such understanding could be the works by A. Oparin $(1967 ; 1968 ; 1977)$. This author considers purposefulness to be a general elementary property of structures and functions of living matter at all levels of its organization. Purposefulness is the fact exposed to our experience and like the other biological facts requires the scientific explanation (Ślaga 1979: 261). Excluding the mechanistic concepts and the influence of randomness or "plan of creation", Oparin assumes that the key mechanisms explaining the genesis of the purposive organization of biostructures are specific interactions of organism and its environment as well as the influence of natural selection. Such biologically at the first glimpse of eye satisfactory assumption is able to arouse suspicion about interpreting the purposive activity attributed to evolution as the goal-directed activity (Lenartowicz 1986: 208). Consequently because of the doubtfulness of the teleological explanation of the action of natural selection smoothing over the difference between directedness and porpose would lead to vicious circle.

The purposive activity of biosystems to which we limit here can not be understood intuitively and with common sense. The analysis of the activity of that type only then satisfies the conditions of being comprehensive, heuristic and scientifically efficient when it is made within and with reference to the specific theory of the organization of biosystems.

In this way in considerations on teleology we have to do with two concrete united tasks: 1 . choice of the appropriate theory of biological organization, 2. to show factual references of the teleological enunciations within the applied theory.

The first task is not difficult because the system ideas of organization have acquired the civil rights in biology and have freed it from the enormous influence of the mechanistic stream, where the meristic-analytical approach was typical. The overcoming of the onesidedness of such views was due to L. von Bertalanffy, who is thought to be a creator of the organismal-system biology. 
The ideas of wholness, system, and equifinality allowed to interpret organism as a system of complex and hierarchically organized structure aiming at maintenance of the dynamic equilibrium.

The second task, more difficult, concerns the question of the "empirical" base of teleology that is about what - in the concrete biological theories which employ the principles of the general system theory, theory of information or biocybernetics and concerning living objects, their parts and processes - is interpreted and explained teleologically.

Problem of the empirical base of teleology ("what") could be, as it seems, solved adequately with the Bunge's theory (formulated for the physical sciences) which specifies the concept of factual reference of the theoretical constructs (Bunge 1973; 1976). By travesting of this concept over to the domain of biology we would show the references which are the indirect factual referents which are the defined characteristics of objects and real processes and not direct referents, namely the model objects which together with the applied general theory make the theoretical model (construct). In the case of theory of biological organization we have not the single objects as the referents but the classes of nonhomogenic referents concerning various types of structures, parts, processes, events. Considering the logical structure the theory of biological organization like some other theories is the hipotetical and deductive system of propositions and that is why we should define the function which enables us to find the referents of predicats and propositions. If, what always take place they are complex should be analysed by means of the clases of references of the predicats and simple propositions. The sum of these latter ones should be equal to the classes of factual references of the complex construct (Szala 1988: 124-125). This type of analysis which are not made here allow similarly to physics (Bunge 1975: 8081) to avoid the subjective elements in the interpretations of the theoretical statements within the teleology of structure and the organization of biosystems.

\section{THE OUTLINE OF THE SYSTEM THEORY OF BIOLOGICAL ORGANIZATION}

From the biological point of view in the interpretation of the essence of life at all we sum up as a rule the co-called essential features attributed to all the living beings and only to them. In this way we have the general picture of what we call the life of an organism. Usually we mention the features of life such as ability to moving, development, transfer of the genetic information, variability, evolution. These abilities even taken together, do not make any universal criterion of life since the certain organisms show some of those aspects and some only periodically and in the state of anabiosis they are so reduced that even imperceptible (Ganti 1986: 17-23, 82-88). With time they come to a conclusion 
72 that to make an precise and united theory it is not enough to analyse and sum up the particular parts and its properties and that is why this way was replaced by understanding of the structure of an organism as the indivisible wholeness. Although organism as a whole consists of parts and units but "'its essence is not made with the properties of its elements but with specific system of relations of the elements for this wholeness" (Strzałko 1980: 17-18). The features of an organism as a whole are the result of the inner order and the interrelations of the elements and not the simple sum of their properties. To proper understanding of the essence of any living organism and the life itself we need the system approach which seems to be the most adequate. In Bertalanffy's opinion (1960: 12-13) the principles of life are the laws of organization joining the different features together in a form of one functioning and dynamic system. The living beings are defined as the wholeness-system of proper level of complexity and organization. According to the level of complexity functions and reactions of a given biosystem are controlled with the laws of not only lower degree (of sublevels) but also laws specific for this level. There are not only the physico-chemical laws but essentially biological different for the various types of biosystems. It is because these laws and the basic concepts are defined within the system approach enough generally to be applied to the particular levels of the organization of the living matter. Since the life exists only in the material objects showing some organization that is why the concepts and the laws defining the given groups of properties must reflect the type and level of this organization. We mean here such connections and reactions which create every system to be an organic wholeness able to relatively independent existence in a form of biosystem within which life is a process of "self-improvement" (Wiedienow, Kremianski 1973: 185).

Life is treated in system approach as a process of changes taking place in the organized comprehensive system. More precisely, life is a complex and progresive process of the organization of the whole-system hierarchically ordered being able to self-preservation, reconstruction in time accordingly to its own information, reproduction, adaptation and evolution.

Such understanding of life and living organism results from the employment of the concepts and principles of the general system theory and the theory of information in biology. They allow to attribute the certain specific systemic features to organisms.

$1^{\circ}$ - Living organism is defined as a system that means a set of elements ordered in a specific way and the parts interacting with one another and making a certain wholeness. In comparison with inanimate objects which inner order is constant, living systems are the wholenesses showing considerable changeability of the order of their elements and therefore their inner structure is indefinable, we can only define their form as the wholenesses (Stuchliński 1979: 76).

$2^{\circ}$ - Organism as a wholeness is an open system. "It maintains itselfin a continuous inflow and outflow, a building up and breaking down of 
components, never being, so long as it is alive, in a state of chemical and thermodynamic equilibrium but maintained in a so-called steady state..." (Bertalanffy 1968: 38). Processes of the accumulation and expending of the energy guarantee preservation of structure, growth and performance of all the specific functions of a biosystem.

$3^{\circ}$ - Along with the energetic processes in a biosystem we have accumulation, transformation and employment of information. The information and control mechanisms determine which energetic processes must be used with what speed and intensity in order to satisfy the conditions favourable to an appropriate work of a biosystem in a changing environment (Nowosielcow 1978: 17).

$4^{\circ}$ - Organism as an informative and controlling system constantly exchanging matter, energy and information with environment opposing to the growth of entropy so it is a negentropy system. The negentropy processes being in opposition to the tendency of maximum disorder are closely related to a growth of the quantity of information (Sietrow 1975), and in this way they proceed in increasing of the order and organization. By means of these different kinds of regulations a biosystem achieves the order because of the dynamic interactions of the processes.

$5^{\circ}$ - Living organism as an open system is characterizes by a stationary state (quasistationary) showing the ability to keep itself as a wholeness in a dynamic equilibrium in spite of the continual flow of energy and matter. In this state it does not undergo any changes in time as a wholness despite of the changing conditions; it keeps itself at the constant level far from the state of real equilibrium in continuous ability to work.

$6^{\circ}$ - As a quasi-stationary system organism shows the equifinality understood as the ability of a biosystem to achieve the final state (just steady state, homeostasis) in many ways and in the various initial conditions. Equifinality is characteristic of a dynamic order of the biological processes which are not closely determined by the initial state or the conditions of their progress. In this sense organism is said to be the goal-directed system and this "goal" is to keep stability as the most favourable state to work and to adaptation in changing conditions.

$7^{\circ}$-We understand adaptiveness as the property of a biosystem which enables it to respond to the changes of a system and the states of environment advantageous to its surviving and further existing (Zięba 1980: 33). Self-organization is exactly the ability of a system to improve its structure in order to achieve higher stability and adaptiveness.

In the systemic and informative perspective we can say that the wholeness and organization are the specific principles of order and dynamics of biosystems. Owing to the employment of information and various mechanisms controlling the work and interaction of the sybsystems and co-ordination in time of the various reactions a biosystems shows the property of self-preservation and also the ability of renovation and adaptation to the conditions of an environment. 
In the system view of biological organization one stresses the wholeness and the dynamic character of the inner structure of biosystems. The discussed properties of the organic wholeness clearly dominate over the parts, the wholeness preserves its state, exists despite of the continuous changes of parts and elements and the multiplicity of reactions and processes determining the dynamics of a system is strictly integrated and undergoes the various controlling mechanisms connected inseparably with this "superior" wholeness (Stuchlinski 1979: 80-82). Organization and the inner dynamics aims at deeping the matter and energy at the constant level, proper conduction and regulation of the various processes, preserving the stationary state (homeostasis) that means preserving biosystem alive and even developing it as a wholeness.

\section{EQUIFINALITY AND THE INFORMATIVE PROGRAM}

In the mentioned above systemic and informative treatment of biological organization we have had the terms such as: the structural and functional order, inner dynamics, order and coordination of the processes, achievement of the final state etc. Terms of this type are irresistibly aiming at the question about the goal and the directedness. Is the stationary state a goal of a biosystem? and are the complex processes goal-directed to gaining such state?

It seems that the delineated system characteristic of an organism suggests univocally a positive answer. If we assume and it is a simplified version that the whole of the complex structural and functional, inner dynamic, co-ordination and the order of processes properties express themselves in the ability to achieve a final state that means equifinality we have reason to think that the teleonomic aspect is an objective property of biosystems. It would refer to Bertalanffy's dynamic teleology $(1950: 159 ; 1968: 78)$ which indicates the directiveness of the processes and includes a) direction of events towards a final state which can be expressed as if the present behaviour were dependent on that final state and b) directiveness based upon structure, meaning that an arrangement of structures leads the process in such way that a certain result is achieved. Biosystem in its functional integrity aims at its self-preservation and its goal is the final state which it achieves as a result of its functioning on the basis of its own structural organization.

In the mentioned system approach the concept of equifinality si surely a step forward in defining teleonomy of biosystems in comparison with the concepts of various servomechanisms, feedback or homeostasis.

Equifinality as the system property is yet too general idea to be employed without ambiguity in biologist's research work. We have an irresistible need of the biological substantiation of the general idea. This substantiation seems possible to realize by attributing the concepts of program and the realization of 
the information included in it to equifinality. It would be an attempt to join the two explicitly distinguished by Nagel (1979:281-285) opinions about the essence of the goaldirected processes: general system view and "informative-program" one. It is indicated above that the inner dynamics and the adequate co-ordination of the various processes which take place in biosystems is done under the influence the various regulating and controlling mechanisms. These particularly can function because of the adequate inner or outer information. So we may say that the processes in a biosystem appear controlly with a program and they are aiming at the goal delineated by the information encoded in that program.

The idea of program in biology is developed by E. Mayr (1961; 1974), according to whom teleonomic phenomena and processes are those which goal-directedness owe to work of program treated as the encoded or previously ordered information controlling the processes and leading them to a given goal (Mayr 1974: 98-102). Program presumes some more or less precise reference to the final state. Mayr refers to the programs of two kinds: a) closed - the information content is totally included in the structure of the nucleic acid, the programs are invariable and create the strict patterns of functioning, b) open information is acquired through experience, learning. The two kinds of programs are not the causes of the processes but they perform regulative functions of their aiming at the goal which could be delineated structure, function, activity.

Mayr's concept of the program of the goal-directed processes has been estimated many times among the others by E. M. Engels (1982: 188-202). This author, however, refers to some critical opinions formulated earlier by Nagel. In this author's opinion (Nagel 1974: 283-285) there are a great number of difficulties in the mentioned Mayr's concept mainly connected with the goal-directedness which can not be defined in terms of elements and the structure of DNA molecules, defined sufficiently to be distinguished from the other types of processes. It seems that these difficulties can be avoided at least partially owing to the proposed here system approach of the purposively programed biotic processes Such understanding is based on not only a simple connection of Mayr's concept with L. von Bartalanffy's ideas but on the elaboration of the adequate principles of recognition and the criteria of acceptation of the structures and processes as goal-directed on the base of the properties of a biosystem and its specific organization.

\section{HIERARCHY OF GOALS AND CRITERIA OF PURPOSEFULNESS}

1. Before we make an attempt to formulate the criteria of recognition in the possibly univocal way of the process as goal-directed and the system as teleonomic it seems necessary to identify the final state as the goal at which 
76 system aims. The most probable way of such identification is showing at least by way of example which goals are ascribed by a biologist in his research work to systems, structures or processes.

Generally we consider final state to be a goal of a biosystem which it achieves owing to its organization and functioning and it is the preservation of the steady state. In this understanding analysis of goals renders as it is shown above by the analysis of the specific properties of systems in their final states. Multiplicity of these properties and the different levels of organization generate the multiplicity of goals. Relatively to the hierarchic organization of biosystems we can say about hierarchy of goals (Mesarovic 1968:69). The global goal of a system is thought to be an unusual activity and preservation of its life that means the aiming at the self-preservation. The property renders by keeping on one hand the proper state of "the inner environment" and on the other hand the balanced flow of matter and energy. Indirectly the goal of a system is the preservation of the most favourable functioning so effectiveness, reliability, economic management (Novosielcov 1979: 33). In this author's opinion the hierarchy of goals in a biosystem can be interpreted roughly in the folloving way. For the general self-preservation of a biosystem the most important and firstly achieved is the ability to preserve the non-equilibrium steady state owing to which we have a preservation of a speed of the flow of energy and matter from the outside and expulsion into the outside. Then, however we have another goal, hierarchically lower as a possibility of preservation of the state (homeostasis) of inner environment. The first goal is achieved through the wide range of the changes of the environmental conditions. If these two goals are achieved then is realized the third one, the lowest. That means the possibility of the progresive improvement of the quality of processes in a system. However we have problems in the precise indication of the bounds of these ranges (Novosielcov 1978: 35-37). As the proper conditions in a biosystem decrease it is possible to renounce the hierarchically less important goals connected with having the opotimum characteristics. Further diminution of the hierarchically lower goals leads to the loss of the guarantee of preservation of the inner stationary discipline and then the live processes are maintained for a defined time by means of the reserves of energy and matter in a system. In this author's opinion 'concept of 'the preservative ability of the biosystem' is the connection of two concepts: the ability of a system to protect homeostasis and the ability to maintain the non-equilibrium steady state in the changing conditions of the auther environment" (Novosielcov 1978: 50). Generally from system point of view we can say that the simpler goals are achieved with the simple structure and simpler organization and the superior and more complex goals need more complex structure and superior organization of this structure or system.

2. From the given above more important goals and their hierarchical system we can try to distinguish the most characteristic features and those ones which 
are mostly taken as the grounds for formulating of so-called criteria of the acceptance of systems and biological processes as goal-directed.

In this case we have a great divergence of opinions. Accordingly to Hull's (1974: 103) a list of the necessary criteria enough to accept a system as a purposeful is not possible to make since we haven't discovered yet the essence of the teleonomic systems. In this research worker's opinion the teleological problem can be understood empirically when we analyse the systems traditionally treated as purposeful and we search for certain properties characteristic for these systems. He shows four such properties which create two pairs. The first pair of properties is created with the definition a) functional - rendered by the frequency at which some privileged or purposeful states of a system are achieved with the different changes both in the system and in the environmment, b) structural - in the terms of causal mechanisms (the feedback, especially negative) generating such preferable states. Another pair of the properties is created with the definitions c) historical - indicating the genesis of the teleonomic system in the cours of the selective processes and d) structural - expressed with the terms of programs (Hull 1974: 102). After the negative evaluation of these properties the author concludes that the bound between the teleonomic and nonteleonomic systems is not very clear and the criteria themselves are too confused.

Somehow different is Beckner's opinion who on the base of G. Sommerhoff s analysis (1950) formulates a criterion of activity so as to satisfy the necessary and sufficient conditions and include some reference to the empirical character of the activity and the nature of the working system (Beckner 1972: 89). In his opinion the purposeful activity appears only when the goal is and the system shows the persistence in achieving of this goal (as a result of the directed correlation of the processes) and sensitiveness to the conditions which maintain or hinder achieving of this goal (Beckner 1959: 143). The other authors refer to concept of the persistence in achieving of a goal too such as R. Braitwaite (1953: 144) and E. Nagel (1979: 286; 1970: 359), adding to this feature another one that means plasticity of the process rendered by the fact that generally a system achieves the some goal in various ways and coming from the different initial conditions so in different circumstances by means of the alternative forms of activity and often employing different causal chains. R. Braitwaite after Russel (1945: 110) explains descriptively the criteria of purposefulness and processes in the following way. Goal is the end of an action and the activity stops along with the achievement of a goal. If the goal is not achieves then the activity goes on. The cours of the activity can undergo the changes because a) if a goal is not achieved with one of the methods the other ones can be employed, b) when a goal is usually achieved with a set of means (causes), lack of one of them can be compensate with the wider employement of the other means. Furthemore different ways and different initial conditions can lead to the same goal, the 
78 initial state is considered to be a more constant element than the means which cause it (Stopa 1988: 225-226).

Another criterion is formulated by Ayala (1970: 12-13) that means the criterion of usefulness. In accordance to it a given feature or process is teleonomic if it is useful for the system in which it appears and if this usefulness explains the presence of this feature or process in this system. In biosystems such usufulness in the sense of inner teleology that means adequate for a system immanently refers to preservation and reproduction. Certain features of biosystems show adaptiveness and usefulness and not by themselves but owing to the fact that they accompany or accompanied in the past the other adaptive or useful properties.

The set of the mentioned properties treated jointly allows for the general atribution of the teleonomic character to systems and biotic processes although it does not seem to be sufficient criterion for their proper and univocal delimitation in relation to the nonteleonomic systems and processes. It surely results from the multiplicity of the types of biosystems and the processes which appear in them and so the multiplicity of goals and still insufficient knowledge about biological objects and their activity. And the problem is yet complicated by terminological diversity and interpretative differences brought about by some theoretical and philosophical approaches.

\section{DISCUSSION AND CONCLUSIONS}

Considerations on teleology limited here to the objective and theoretical aspects on one hand and to the least questionable organismal level have not led to definitive solutions, maybe just to specification and proper-for the comprehensive treating of the purposefulness - distribution of the fundamental questions.

And so in the first place we stress a fact that the peculiar system and informative organization of biosystem and its specific activity give the reasosns for its aiming at a goal and its structure and processes are goal-directed. Such definition of both the global and particular goals needs the knowledge about the actual state of a system and the regularity of the activity of the multiple processes and therefore their causes and mechanisms.

Then it is shown that in the structure of the teleonomic systems and in the equifinal processes the first place is taken by information which has here the control and steering tasks over the regulating mechanisms. In this concept a goal encoded in a program is an informative cause of the result of controlling. It contributes to the changes of parameters of a system in the controlling process and to choice of the defined variant of an activity. A real program of controlling "anticipates" the future of a system and bases on the transformed information of the outer conditions which are for it a functional standard alsso in future. Hence information along with the activity of the various causes and mechanisms is the 
essential element for the achievement of a goal which is the preservation of the existence of a biosystem.

The delineated informative and systemic interpretation of teleonomy is connected closer than in the other concepts with the inner structural and functional organization with which we interpret the essence of life itself today. In this way teleology indicates ' property that not only exists in a biosystem but specifies it well" (Wysocki 1988: 212). In this context Sattler (1986: 152) is right who states in the margin of the debates over teleology that they have no pure semantic character but they are "a debate over the nature of living systems".

From the above considerations we know that the base of the purposefulness in biology is a specific organization of biosystems and biotic processes. It is an empirical base, an unique factual reference of the teleological concepts and at the same time the starting-point to a formulation of the criteria of treating biosystems as teleonomical and the processes as goal-directed. Further precision of these concepts and criteria analysed among others by P. Calow (1976) should lead to a transformation of the assumed here objective plane into methodological and to show "'the explanatory power" of such approaches (Wysocki 1988: 219).

Presumably not all the teleological concepts are the explanations and they need further explanation of a different type. Moreover it can happen that the concepts recognized unguestionably as goal-directed explanation needn't to be oppositive but complementary to the causal explanations. But this problem similarly to the complex one ofexplanation of the genesis of the teleonomic properties necessitate separate critical analysis.

\section{BIBLIOGRAPHY}

Ayala F.:Teleological explanation in evolutionary biology, Philos Sci. 37 (1970) 1-15.

Ayala F.: The autonomy of biology as a natural science, in: Biology, history, and natural philosophy, ed. by A. Breck, W. Yourgrau, New York 1974, 1-16.

Ayala F.: Teleological explanations, in: Philosophy of biology, ed. by M. Ruse, New York 1989, 187-195.

Beckner M.: The biological way of thought, Columbia University Press 1959.

Beckner M.: Teleology, in: The Encyclopedia of Philosophy, ed. by P. Edwards, New York-London 1972, v. 8, 88-91.

Berlalanlfy L. von: An outline of general system theory, Brit. J. Philos. Sci. 1 (1950 134-165. Bertalanffy L. von: Problems of life, London 1960.

Bertalanffy L. von: General system theory, Harmondsworth 1968.

Braitwaite R.: Scientific explanation, New York 1960.

Bunge M.: Philosophy of physics, Fordrecht 1973 (russ. transl. Moscow 1975).

Bunge M.: Sense and reference, Dordrecht 1973.

Bunge M.: Znaczenie w nauce (Meaning in science), in: Teoria a rzeczywistość (Theory and reality),

Pozn. Stud. Filoz. Nauki 1, Warszawa-Poznań 1976, 13-23.

Calow P.: Biological machines. A cybernetic approach to life, London 1976.

Engels E. M.: Die Teleologie des Lebendigen, Berlin 1982.

Ganti T.: Podstawy życia (The principles of life), transl. by T. Kudasiewicz, Warszawa 1986. Goudge T. A.: The ascent of life. A philosophical study of the theory of evolution, Toronto 1961. Hull D.:

Philosophy of biological science, Englewood Cliffs 1974. 
Lalande A.: Vocabulaire technique de la philosophic, Paris 1962.

Lenartowicz P.: Elementy filozofii zjawiska biologicznego (An outline of the philosophy of biological event), Kraków 1986.

Mayr E.: Cause and effects in biology, Science 134 (1961) 1501-1506.

Mayr E.: Teleological and teleonomic, a new analysis, in: Boston St. Phil. Sci. XIV, ed. by R. Cohen, M. Wartofsky, Boston 1974, 91-117.

Mesarovic M.: Systems theory and biology, view of a theoretician, in: Systems theory and biology, ed. by M. Mesarovic, Berlin-New York 1968, 59-87.

Nagel e.: Struktura nauki (The structure of science), Warszawa 1970.

Nagel E.: Teleology revisited and other essays in the philosophy and history of sicence, New York 1979.

Novosielcev W.: Teorija uprawlenija i biosistemy. Analiz sochranitielnych svojstv, Moskwa 1978.

Oparin A.: L'origine et 1'evolution de la vie, Mpscou 1967.

Oparin A.: Powstanie życia na Ziemi (Origin of life on Earth), transl. J. Nowicki, Warszawa 1986.

Oparin A.: Matieria, żizn, intelekt, Moskwa 1977.

Ruse M.: Philosophy of biology today, New York 1988.

Russell E.: The directiveness of organic activities, Cambridge 1945.

Sattler R.: Biophilosophy. Analytic and holistic perspectives. Berlin-New York 1986.

Sietrov M.: Informacionnyje processy w biologiczeskich sistemach, Leningrad 1975.

Stopa A.: Problematyka celowości w ujęciach R. Braitwaite'a i E. Mayra (The problem of teleology according to Brailwaite and Mayr), in: Z zagadnień filozofii przyrodoznawstwa i filozofii przyrody (Problems of the philosophy of natural science and the philosophy of nature) ed. by M. Lubański and Sz. W. Ślaga, v. X, Warszawa 1988, 221-239.

Strzałko J., M. Henneberg, J. Piontek: Populacje ludzkie jako systemy biologiczne (Human populations as a bilogical systems), Warszawa 1980.

Stuchliński J.: Problem wyboru strategii metodologicznej w biologii współczesnej (The choice of methodological strategy in modern bilogy), Warszawa 1979.

Szala A.: Odniesienie przedmiotowe teorii fizykalnych (Factual reference of physical theory), in: $\mathrm{Z}$ zagadnień... (Problems of philosophy...), ed. by K. Lubański and Sz. W. Ślaga, v. X, Warszawa 1988, 121-135.

Ślaga Sz. W.: Problem istoty życia w teorii abiogenezy A. Oparina, (Problem of the nature of life in Oparin's theory of abiogenesis), in: Z zagadnień (Problems of philosophy...), ed. by K. Klosak, v. Il, Warszawa 1979, 217-263.

Ślaga Sz. W.: What the philosophy of biology is and should be?, Studia Philos. Christ. 25 (1989) nr 2, 155-175.

Wiedienov W., W. Kremianski: Kryteria poziomów strukturalnych w biosystemach (The criteria of the structural levels in biological systems), in: Problemy metodologii badań systemowych (Problems of methodology of system researches), Warszawa 1973, 181-195.

Woodfield A.: Teleology, Cambridge 1976.

Woodger J.H.: Bilogical pronciples, New York 1967.

Wuketits F.: On the notion of teleology in contemporary life sciences, Dialectica 34 (1980) no. 4, 277 290).

Wysocki J.: Zagadnienie celowości procesów biologicznych (The problem of teleology of biological processes), in: Z zagadnień... (Problems of philosophy...), ed. by M. Lubański and Sz. W. Ślaga, v. X, Warszawa 1988, 209-220.

Zięba S., W. Jarominek, R. Staniszewski: Problemy teorii systemów (Problems of system theory), Wroclaw-Warszawa 1980. 